\title{
Film Slide Rule
}

Mechanical aids to computation are generally divided into two classes, namely, discrete devices and continuous devices. The former class includes the desk calculator and other machines based on a counting process. The latter includes such instruments as the ordinary slide rule and others that depend upon measurement of some continuous quantity like length. Discrete computing aids are characterized by accuracy that is theoretically unlimited, being bounded in practice only by bulk and cost, whereas continuous devices are limited by the inherent errors in the measurement of the basic physical quantity.

There appear to be very few aids to computation that combine the two principles. One combination instrument was devised by the writer while acting as Technical Aide to the National Defence Research Committee (NDRC). The objective was an instrument capable of handling functions, such as $\log x, x^{2}$ etc., with errors roughly one tenth those of the ordinary $20^{\prime \prime}$ slide rule, and with less eye strain and fatigue.

The resulting instrument is called the "Film Slide Rule," and, as its name implies, it uses movie film as the base for slide-rule scales. Each scale is printed on a separate film approximately 220 feet long and the films are wound on take-up reels.

If the films were laid side by side as in an ordinary slide rule, and a solution obtained by measuring off lengths of film, then the device would be an ordinary continuous computer. It would be subject to errors due to expansion of the film etc. Instead of making the length the basic quantity, therefore, we use the teeth on a sprocket that carries the film as basic. These are discrete units that can be counted, and not measured. The scale on the film acts in a dual capacity: primarily, it counts the sprocket teeth that pass under a fixed mark when the slide rule is set, and secondarily, it measures fractional parts of the distance between sprocket teeth. Finally, the scale defines a function of the basic variable.

Film Slide Rules have been made in various sizes, with three to ten films on each, and with appropriate mechanical connections between the sprockets to solve various problems. Scales have been made up to represent $x^{2}, \log x$, $\log \sin x, \log \cos x$ and $\log \tan x$, for use in solving triangulation problems in two and three dimensions. They have been found to save $80 \%$ to $90 \%$ of the time required for computation by the use of tables and desk calculators, when a large group of reasonably similar numerical values are given. An example of such a set of problems is found in the triangulation of, say, a hundred positions of an object moving in space.

The Film Slide Rule has the disadvantage, common to most continuous instruments, that it must be adapted to a special class of prohlems, and hence is of no value unless a large number of similar problems is to be solved.

393 S. Prospect St., Burlington, Vt.

G. R. Stibitz

Edrorial Note: These models are in use at Fort Bliss, Texas. A description by Army Ground Forces Board, no. 4, Ft. Bliss, was iss'led May 9, 1947 by the Applied Physics Laboratory of The Johns Hopkins. University. A report, Stibitz Computing Machine, Model $B$, Designed and Built by Department of Physics, University of $N$. C., Chapel Hill, N. C., 1944,12 leaves, gives details of the construction and operation. The description of last May, 10 leaves, includes excellent reproductions of photographs of the Ten Film Stibitz Calculator. But the present statement is the first one made for the general public. 